\title{
Dari Novel ke Film: Kajian Teori Adaptasi sebagai Pendekatan dalam Penciptaan Film
}

\author{
Deny Tri Ardianto \\ Universitas Sebelas Maret (UNS) Surakarta \\ Jl. Ir. Sutami 36 A, Kentingan, Surakarta 57126
}

\begin{abstract}
This paper is motivated by the success of the films adaptated from literary works (novels) in captiving audiences and dominating world cinema. For this reason, it is necessary to understand how The Theory of Adaptation is used to transform literary works into visual structure of the film. Based on some adaptation model proposed by the experts, adaptation of literary work (novel) into film can carried out in two ways; first, by focusing on fidelity to the source, and second, by taking into account the contextuality-intertextuality of the source.
\end{abstract}

Keywords: adaptation, transformation, contextuality-intertextuality

\begin{abstract}
ABSTRAK
Tulisan ini dilatarbelakangi oleh keberhasilan film-film hasil adaptasi dari karya sastra (novel) dalam memikat hati penonton dan menguasai pasar perfilman dunia. Oleh karena itu perlu kiranya diketahui bagaimana teori adaptasi itu digunakan dan bekerja dalam mentransformasi struktur teks naskah menjadi struktur visual film. Dari beberapa model adaptasi yang dikemukakan oleh para pakar, dapat diketahui bahwa adaptasi terhadap karya sastra (novel) menjadi film dapat dilakukan melalaui dua cara yaitu: pertama, menitikberatkan pada kesetiaan (fidelity) pada sumber adaptasi; dan kedua, kontekstualitasintertekstualitas sumber adaptasi.
\end{abstract}

Kata kunci: adaptasi, transformasi, kontekstualitas-intertektualitas

\section{PENDAHULUAN}

Apabila dibandingkan dengan sejarah tradisi cetak lima ratus tahun lalu, dan sejarah sastra seribu tahun lalu, sejarah film di usianya yang ke seratus tahun, tampak sangatlah belia. Namun, meskipun teknologi sinema ini relatif baru, fenomena 'gambar bergerak' dengan cepat menjadi ujung tombak budaya naratif. Perkembangan yang cepat itu tidak terlepas dari kontribusi bidang-bidang seni lainnya, terutama seni sastra. Dengan memahami film berarti memahami bahasa ekspresi dari sastra, dan begitu pula sebaliknya bahasa ekspresi dari karya sastra juga banyak dipengaruhi oleh film. Oleh karena itu, tidak heran jika kedua karya seni ini sering terjadi saling mempengaruhi. Banyak karya-karya film yang tercipta dari hasil adaptasi sebuah karya sastra.

Jauh sebelum kemunculan film 'The Birth of a Nation' (1915), sebuah film bisu produksi USA yang disutradarai oleh D. W. Griffith dan merupakan adaptasi dari novel dan teater berjudul The Clansman karya 
Thomas Dixon, Jr, para pembuat film telah melirik karya-karya sastra sebagai inspirasi pembuatan film. Sebagai contoh di Amerika, sutradara Edwin S. Porter dan D. W. Griffith secara berturut-turut telah mengadaptasi novel Uncle Tom's Cabin (1903) karya Harriet Beecher Stowe dan The Pit (1909) karya Frank Norris ke dalam film. Adapun di Perancis, Georges Méliès mengadaptasi novel karya Jules Verne, From the Earth to the Moon (1865) dan novel karya $\mathrm{H}$. G. Wells, The First Men in the Moon (1901) menjadi film berjudul $A$ Trip to the Moon (1902) (Tibbetts \& Welsh. 2005: xv). Sejak 1908-1913, perusahaan film Le Film d'Art Studios di Prancis juga rutin memproduksi film layar lebar dari beberapa versi karya sastra milik Dickens, Goethe, BulwerLytton, Dumas, dan Balzac.

Fenomena serupa juga terjadi di Inggris, sutradara Cecil Hepworth dan Percy Stow membuat versi 16-scene film Alice in Wonderland (1903) dari buku cerita anak-anak berjudul Alice's Adventures in Wonderland karya Lewis Carroll. Hal itu juga terjadi di Denmark, dengan munculnya sebuah film horor berjudul Dr. Jekyll and Mr. Hyde (1909) hasil adaptasi dari novel The Strange Case of Dr Jekyll and Mr Hyde (1886) karya Robert Louis Stevenson. Selanjutnya dari tahun ke tahun kemunculan film adaptasi dari hasil karya sastra semakin meningkat. Fenomena ini berkembang pesat pasca Perang Dunia II (Klemm, 2009: 209). James M. Welsh dan Peter Lev dalam bukunya berjudul The Literature/Film Reader: Issues in Adaptation (2007), menuliskan sebagai berikut:

"After a century of cinema, movies have changed substantially, both technologically and stylistically, but after a hundred years, mainstream cinema is still Telling and retelling stories, and most of those stories are still being (or have been) appropriated from literary or dramatic sources, as much as 85 percent by some calculations and accounts.

Adaptation has always been central to the process of filmmaking since almost the beginning and could well maintain its dominance into the cinema's second century (James M. Welsh \& Peter Lev, 2007: xiii)."

Pernyataan tersebut menegaskan bahwa secara kuantitas film yang menggunakan karya sastra sebagai sumber penciptaan memiliki nilai prosentase yang sangat besar, terutama di Amerika Serikat sebagai arsitektur perfilman dunia.

Morris Beja dalam bukunya Film and Literature: an Introduction semakin menegaskan bahwa fenomena keberhasilan film adaptasi dalam menguasai industri perfilman dunia sudah terjadi sejak kelahiran Academy Award pada tahun 1927 (Beja, 1979: 78). Hal itu juga dijelaskan oleh Giddings dalam $A$ daptations: From Text to Screen, Screen to Text, bahwa tiga perempat film terbaik pemenang Oscar dalam ajang Academy Award merupakan karya adaptasi, dan dari dua puluh film terlaris di tahun 1990, empat belas di antaranya adalah film-film yang mengadaptasi dari karya sastra (Cartmell, 1999: 23). Ditambahkan pula oleh Groensteen dalam The Theory of Adaptation (Hutcheon, 2006: 4) dan Seger dalam The Art of Adaptation: Turning Fact and Fiction into Film (Seger, 1992: xi), bahwa berdasarkan data statistik di tahun 1992 tercatat 85\% film pemenang Oscar merupakan adaptasi dari karya sastra (novel, cerpen, drama, dan lain-lain). Sementara itu, 95\% mini seri untuk televisi merupakan adaptasi dari novel, bahkan 70\% peraih Emmy Award, yakni penghargaan terbaik untuk karya-karya di televisi, juga merupakan hasil adaptasi.

Beberapa film adaptasi yang meraup sukses secara komersial dan meraih banyak penghargaan bergengsi antara lain: Nosferatu (F. W. Murnau, 1922) dan Dracula (Tod Browning, 1931), keduanya adaptasi dari novel Dracula (1897) karya Bram Stoker, sementara film Frankenstein (James Whale, 1931) adaptasi dari novel Frankenstein (1818) karya Mary Shelley, film Gone with the Wind (Victor Fleming, 1939) adap- 
tasi dari novel Gone with the Wind (1936) karya Margaret Mitchell, film Psycho (Alfred Hitchcock, 1960) adaptasi dari novel Psycho (1959) karya Robert Bloch. Film-film James Bond (sejak tahun 1962-kini) berasal dari adaptasi novel-novel karya Ian Fleming (dan penerusnya), yaitu Bond (1953-kini), film The Godfather (Francis Ford Coppola, 1972) adaptasi dari novel berjudul The Godfather (1969) karya Mario Puzo, film trilogi The Lord of the Rings (Peter Jackson, 2001, 2002. dan 2003) adaptasi dari novel The Lord of the Rings trilogy (1954-1955) karya J. R. R. Tolkien, dan masih banyak lagi.

\section{Film Adaptasi di Indonesia}

Terlacak sebagai film hasil adaptasi pertama di Indonesia adalah film Loetoeng Kasaroeng (1926). Film Loetoeng Kasaroeng merupakan film pertama yang diproduksi di Indonesia. Film ini diproduksi oleh NV. Java Film Company disutradarai oleh dua orang berkebangsaan Belanda yaitu, G. Kruger dan L. Heuveldorp yang dibintangi oleh aktor-aktris pribumi (Kristanto, 2006: 1). Setelah itu pada tahun 1931, diproduksi kembali sebuah film adaptasi dari novel berjudul Bunga Roos dari Tjikembang karya Kwee Tek Hoay dengan sutradara The Teng Chun (Kristanto, 2006: 2). Seorang sutradara bernama Lie Tek Swie pada tahun 1941 juga memfilmkan Siti Noerbaja, sebuah novel legendaris karya Marah Roesli, sedangkan sutradara Nico Pelamonia di tahun 1967 juga memproduksi film berjudul Senja di Jakarta adaptasi dari novel karya Mochtar Lubis.

Dekade tahun 1970-an, beberapa film hasil adaptasi mampu meraih sukses yang fenomenal dengan menjaring banyak penonton, misalnya Salah Asoehan (1972) sutradara Asrul Sani yang diangkat dari novel dengan judul yang sama karya $\mathrm{Ab}$ doel Moeis, kemudian film Si Doel Anak Be- tawi (1973) sutradara Sjuman Djaya juga diangkat dari novel dengan judul yang sama karya Aman Datoek Madjoindo. Tahun 1975, film Bunga Roos dari Tjikembang didaur ulang oleh Wim Umboh dan berhasil menjadi film terlaris keempat di Indonesia dengan penonton 117.806 orang. Film ini juga berhasil menyabet Piala Citra Festival Film Indonesia (FFI) 1976 untuk Film Terbaik, Pemeran Utama Pria Terbaik, Editing, dan Fotografi Terbaik.

Novelis wanita Indonesia seperti Marga T. beberapa karyanya juga diadaptasi menjadi film seperti Karmila (1975). Film Karmila disutradarai oleh Ami Prijono, film ini berhasil menembus dan bertahan lama di bioskop kelas atas. Menurut data Perfin, Karmila merupakan film terlaris kedua di Jakarta pada 1976 dengan jumlah penonton mencapai 213.036 orang (www.indonesiancinematheque.blogspot.com). Setelah sukses membesut film Karmila, Ami Prijono meneruskan proyek film adaptasi lainnya yaitu film Cintaku di Kampus Biru (1976). Film Cintaku di Kampus Biru hasil adaptasi dari novel karya Ashadi Siregar. Film ini tercatat sebagai film terlaris ketiga di Jakarta pada 1976 dengan jumlah penonton 168.456 orang. Setahun kemudian Teguh Karya juga sukses mengangkat kisah novel Badai Pasti Berlalu (1977) karya Marga T. Dua tahun kemudian muncul film Gita Cinta dari SMA (1979) arahan sutradara Arizal, adaptasi dari novel dengan judul yang sama karya Eddy D. Iskandar.

Fenomena film adaptasi di Indonesia pun berkembang hingga kini, tahun 2000an perfilman Indonesia semakin dibanjiri oleh karya-karya film adaptasi seperti $C a$ Bau Kan (Nia Dinata, 2002), Eiffel...I'm in Love (Nasry Cheppy, 2003), Gie (Riri Riza, 2005), Ayat-Ayat Cinta (Hanung Bramantyo, 2008), Laskar Pelangi (Riri Reza, 2008), Ketika Cinta Bertasbih (Chaerul Umam, 2009), Sang Pemimpi (Riri Reza, 2009), dan Sang Penari (Ifa Isfansyah, 2011). Belum lagi film yang 
diangkat dari cerpen, seperti: Tentang Dia (Rudy Sudjarwo, 2005) dan Mereka Bilang, Saya Monyet! (Djenar Maesa Ayu, 2007).

Karya sastra yang diadaptasi ke dalam film biasanya adalah karya-karya sastra yang telah populer di masyarakat. Selain karena ceritanya sudah dikenal oleh masyarakat, karya sastra ini sudah memiliki kelompok penikmat atau pembaca fanatik. Selama ini film adaptasi dapat menyedot perhatian penonton, karena para pembaca yang telah membaca karya sastra itu hendak menkonfirmasi imajinasinya dengan visualisasi yang dihadirkan dalam bentuk film, sehingga tidak heran kalau film AyatAyat Cinta (2008), film religi hasil adaptasi dari sebuah novel best seller karya Habiburrahman El Shirazy berjudul Ayat-Ayat Cinta itu telah ditonton oleh empat juta orang dan merupakan film adaptasi terlaris di Indonesia hingga saat ini.

Berdasarkan kenyataan tersebut maka menjadi menarik untuk diketahui lebih mendalam bagaimana karya-karya sastra diadaptasi menjadi bentuk film. Oleh karena untuk mengetahui bagaimana teori adaptasi digunakan dan bekerja dalam mengubah karya sastra (novel) menjadi bentuk film. Dalam hal ini telah terjadi transformasi dari struktur teks menjadi struktur visual. Kajian ini diharapkan dapat dijadikan referensi bagi para sineas Indonesia untuk melakukan proses transformasi tersebut (novel menjadi film). Sehingga karya-karya sastra yang berkualitas dihasilkan oleh para sastrawan Indonesia dapat dihadirkan dalam bentuk film, baik melalui film layar lebar atau pun televisi.

\section{PEMBAHASAN}

\section{Antara Novel dan Film}

George Bluestone, seorang pelopor studi tentang film adaptasi, melalui bukunya Novels into Film (1957) mengatakan 'The Two
Ways of Seeing' atau 'dua cara melihat' yaitu mempertanyakan persamaan dan perbedaan mendasar dalam melihat sebuah film dengan membaca sebuah karya sastra, serta pencarian relasi antar kedua media tersebut (Bluestone, 1957: 1). Berikut dikotomi Bluestone yang dinyatakan di awal tulisannya:

\begin{abstract}
"I have assumed, and attempted to demonstrate, that the two media are marked by such essentially different traits that they belong to separate artistic genera. Although novels and films of a certain kind do reveal a number of similarities...one finds the differentia more startling. More important, one finds the differentia infinitely more problematic to the film-maker. These distinguishing traits follow primarily from the fact that the novel is a linguistic medium, the film essentially visual (Bluestone, 1957: vi)."
\end{abstract}

Bluestone berasumsi dan berusaha menunjukkan ciri-ciri dasar yang membedakan secara genetika novel dengan film. Novel merupakan sebuah medium linguistik, sementara film merupakan medium dengan pendekatan visual. Meski terdapat beberapa kesamaan di antara keduanya, namun pada kenyataannya, perbedaannya jauh lebih mencolok. Perbedaan itulah yang justru menjadi tantangan bagi filmmaker untuk memecahkannya.

Novel dan film secara fundamental juga memiliki perbedaan pada cara melihat, bahan serta asal usul, baik konvensi maupun penontonnya. Menurut Bluestone yang menarik ketika melihat dua medium ini adalah 'terang-terangan kompatibel, namun diam-diam bermusuhan', sehingga ia dan para adaptor melihat adanya tantangan dan potensi besar untuk menyatukan kedua medium tersebut, karena dengan adanya perbedaan, justru kesenjangan antara bentuk-bentuk yang diadaptasi memiliki kemungkinan untuk diterjemahkan dengan lebih kreatif dan konstruktif, karena adaptor bukanlah hanya sekedar penerjemah, melainkan seorang penulis baru (Jenkins, 1997: 15). 
Deborah Cartmell dan Imelda Whelehan dalam Adaptations: From Text to Screen, Screen to Text, menunjukkan bahwa masalah yang paling penting dalam adaptasi karya sastra menjadi film adalah kesetiaan pada sumber aslinya - novel. Dalam buku ini, Whelehan mencoba memecah alur pemikiran yang dimiliki para kritikus dan para pecinta film, dengan menunjukkan bahwa teks lebih penting dari film, di samping menunjukkan perbedaan dan nilai dari setiap media. Dia menyatakan bahwa terdapat banyak 'realitas praktis' yang terlibat dalam mengubah teks menjadi sebuah film yang sukses secara komersial, seperti penggubahan budaya anakronistik (tidak kronologis) dalam penulisan novel dan penggubahan budaya penceritaan naratif novel yang terstruktur dan klasik menjadi penceritaan sebuah film bergenre populer atau dikenali oleh pasar film (Whelehan, 1999: 4).

Seorang kritikus film, Gabriel Miller, memandang film adaptasi sebagai 'proses penyederhanaan' dari novel. Ia yakin film tidak dapat menangani kompleksitas (seperti pikiran, memori, mimpi, atau psikologis) seperti sebuah novel. Pendapat Miller mendapat sanggahan dari Whelehan dengan mengatakan bahwa Miller tidak tahu benar cara kerja dan strategi film, karena asumsi fiksi dapat menangani masalah tersebut dengan 'cara transparan yang tidak memerlukan mediasi buatan' (Whelehan, 1999: 6). Whelehan percaya bahwa film mampu memperoleh makna mendalam melalui penggunaan metafora atau simbolisme. Dia menyatakan bahwa untuk mencapai keberhasilan adaptasi dari sebuah novel, fitur tertentu yang dianggap arti penting dari novel ini harus diterjemahkan dalam film.

\section{Adaptasi Novel Menjadi Film}

Linda Seger dalam The Art of Adaptation Turning Fact and Fiction into Film, menulis- kan bahwa adaptasi merupakan sebuah proses transisi, pengubahan atau konversi dari satu medium ke medium lain (Seger, 1992: 2). Dia tidak lagi menyoal soal beda dua medium, teks dan film, karena sejak awal keduanya memiliki karakter yang berbeda. Sehingga ketika dipersatukan atau dipertautkan sudah dipastikan akan menghasilkan suatu perubahan. Namun, meski pada akhirnya akan muncul sebuah bentuk atau sifat baru sebagai hasil adaptasi, roh dari teks asli diharapkan tetap hadir dalam karya baru tersebut. Seger menyebutnya "take me as I am". Ditambahkan oleh Seger bahwa di dalam adaptasi terdapat tiga proses yang perlu mendapat perhatian, yaitu; rethinking (berpikir ulang), reconceptualizing (mengkonsep ulang), dan understanding (pengertian) atas teks sumber adaptasi.

Sama dengan Seger, Susan Hayward dalam Cinema Studies: The Key Concepts menjelaskan bahwa film adaptasi (dari karya sastra) merupakan sebuah film yang ide ceritanya berangkat dari karya sastra (baik novel, cerpen, dan sebagainya), namun dalam penceritaannya muncul kemungkinan cerita baru yang tidak harus sama persis dengan karya aslinya. Sehingga sebuah karya film adaptasi tetap memberi ruang interpretasi bagi pembuat naskah film ataupun sutradara dalam menerjemahkan naskah aslinya. Sebuah film yang berangkat dari karya sastra tidak hanya fokus pada teks saja, melainkan juga pada medium gambar dan suara.

Lebih jauh Susan menegaskan, meskipun kebebasan dalam menginterpretasi itu ada, namun unsur mise-en-abyme atau inti dari ide cerita asli tetap harus terjaga dalam cerita baru tersebut. Berikut rumusan adaptasi menurut Susan Hayward: teks asli $\left(\mathrm{T}^{1}\right)$, teks adaptasi $\left(\mathrm{T}^{2}\right)$, teks film $\left(\mathrm{T}^{3}\right)$, teks sutradara $\left(\mathrm{T}^{4 \mathrm{n}}\right)$, teks bintang (actor-aktris) $\left(\mathrm{T}^{5 n}\right)$, (kon)teks produksi $\left(\mathrm{T}^{6 \mathrm{n}}\right)$, dan dari beberapa teks menjadi interteks diri $\left(\mathrm{T}^{7 \mathrm{n}}\right)$ (Hayward, 2006: 14). Susan juga membagi 
adaptasi film dari karya sastra menjadi tiga kategori: pertama, adaptasi atas karyakarya klasik atau tradisional, kedua, adaptasi drama panggung atau teater ke film, dan yang terakhir adalah adaptasi karya sastra kontemporer, termasuk di dalamnya karya-karya fiksi popular (Hayward, 2006: 12). Menurut Susan, ketiga kategori tersebut pada umumnya saling berintegrasi satu dengan yang lain, mengingat pada masa kini sebagian besar kreator selalu ingin menampilkan karya sesuai dengan konteks kekiniannya meski cerita berpijak dari cerita klasik atau tradisional.

Adapun Patrick Faubert dalam sebuah jurnal yang berjudul 'Perfect Picture Material': Anthony Adverse and The Future of Adaptation Theory, menyatakan bahwa adaptasi merupakan sebuah bentuk dialog budaya yang selalu mengalami peningkatan kualitas, sehingga tidak patut jika hanya diposisikan sebagai perpanjangan tangan, atau derma dari keberhasilan medium sebelumnya. Beberapa teoritiker yang setuju dengan pendapat Faubert antara lain; Julie Sanders, Robert B. Ray, dan Linda Hutcheon. Mereka berpendapat bahwa adaptasi akan medapatkan posisi lebih bagus jika diinvestasikan sebagai proyek budaya dari pada dieksploitasi sama seperti karya sebelumnya (Faubert, 2010: 182).

Kritikus sastra Julie Sanders memberikan tawaran sebuah karya baru hasil adaptasi sebagai sebuah karya transformasi yang sepenuhnya baru, sebagai sebuah produk kultur yang baru dan mendominasi. Sanders membaca adaptasi sebagai sebuah bentuk transformasi yang terfokus pada proses mengedit dan merevisi sumber untuk membawa mereka keluar, dan menemukan pencerahan baru (Sanders, 2006: 1819). Demikian pula dengan Robert B. Ray, ia mengusulkan adaptasi sebagai tindakan 'mengutip' sebuah karya yang ada, dalam sebuah konteks 'ketidakbersambungan' yang baru, sehingga hasilnya sebuah karya yang benar-benar baru, bukan sekedar 'cover version' (Ray, 2000: 44-46).
Kedua penalaran tersebut disuarakan lagi oleh Linda Hutcheon yang berpendapat bahwa adaptasi selalu ada di ruang lateral bukan linier, dan dengan adaptasi kita mencoba keluar dari mata rantai sumber yang hirarkis (Hutcheon, 2006: 171). Artinya adaptasi bergerak melampaui kesetiaan (pada sumber asli). Hal itu sesuai dengan pernyataan Hutcheon di halaman awal bukunya A Theory of Adaptation, bahwa adaptasi adalah mendekor ulang dengan variasi tanpa meniru atau menjiplak, mengadaptasi berarti mengatur, mengubah, membuat menjadi sesuai (Hutcheon, 2006: 7). Hutcheon menilai bahwa setia pada sumber tidak lagi produktif, karena hanya menghasilkan kerugian dan kebosanan.

Hutcheon mencoba membongkar dan memetakan gambaran-gambaran penting dari seluruh proses adaptasi, tentang apa, siapa, mengapa, bagaimana, dimana, dan kapan melacak keterkaitan media atau karya yang kini ada (baru muncul) berdasarkan media atau karya-karya yang telah ada sebelumnya. Dengan demikian, Hutcheon tidak hanya mengevaluasi adaptasi dengan mempertimbangkan narasi saja, tetapi juga media yang disajikan. Hutcheon juga mengidentifikasi bahwa yang terpenting dalam industri hiburan kontemporer adalah pola konsumsi media yang berulang-ulang dalam berbagai bentuk. Oleh karena itu adaptasi lebih unggul dan mampu mendominasi, karena wilayah cakupannya luas dan tanpa batas. dari film, video game, televisi, website, dan sebagainya.

Hutcheon membagi adaptasi menjadi sebagai sebuah produk, sebagai proses kreasi dan sebagai proses resepsi. Berikut penjabarannya:

- Adaptasi sebagai produk, artinya transposisi dari satu karya (medium) ke karya lain (medium). Misalnya: adaptasi dari novel ke film (tanpa variasi).

- Adapatasi sebagai proses kreasi, artinya sebuah proses adaptasi yang di 
dalamnya terdapat proses interpretasiulang dan kreasi-ulang yang berfungsi sebagai usaha penyelamatan atau penyalinan sumber aslinya. Misalnya: adaptasi dari cerita rakyat (oral) ke dalam bentuk buku atau film.

- Adaptasi sebagai bagian dari proses resepsi, karena adaptasi merupakan bentuk dari intertektualitas karya sastra. Dalam hal ini adaptasi adalah manuskrip atau teks yang melekat pada memori kita yang bukan (langsung) berasal dari sumber asli melainkan berasal dari karya-karya (dalam bentuk) lain, melalui pengulangan-pengulangan yang bervariasi. Misalnya: Film Resident Evil (2002) karya Paul Anderson akan memberikan kepada penonton pengalaman yang berbeda bagi orang yang menonton dan memainkan game dengan judul yang sama, dibanding orang yang memainkan game-nya tetapi tidak menonton filmnya. Keduanya akan sama-sama memiliki pengalaman menikmati atau memainkan Resident Evil meski medium yang mereka hadapi berbeda.

Selain membahas tentang proses dan jenis adaptasi Linda Hutcheon juga menjelaskan tentang bentuk hubungan medium dengan penikmatnya, ia membaginya menjadi tiga bagian, pertama: to tell (menceritakan); berhubungan dengan narasi dalam bentuk teks atau literatur, di mana imajinasi diatur oleh teks, dan tidak dilengkapi gambar dan suara. Namun pembaca bisa berhenti membaca dan berimajinasi sesuai kemauan, selain juga bisa dipegang dan dirasakan dengan tangan. Pembaca juga bisa memilih urutan cerita atau urutan halaman yang ingin dibaca. Kedua: to show (mempertontonkan); merupakan bagian dari film dan pertunjukkan panggung/pentas. Penonton terjebak dalam ketidakberdayaan karena dipaksa untuk mengikuti alur cerita sesuai konsep atau line pertunjukan. Mode ini juga mengubah imajinasi ke dalam re- alitas langsung melalui persepsi penonton. Visual dan gestur merepresentasikan sebuah kesatuan medium yang kompleks. Musik pengiring, dialog, dan pembangunan emosional karakter memprovokasi penonton untuk terlibat secara emosional dalam penceritaan yang dibangun.

Ketiga: interact with stories (berinteraksi dengan cerita); merupakan pembangunan relasi medium dengan target sasaran yang tidak hanya dengan diutarakan atau dipertontonkan saja, melainkan penggabungan keduanya. Sebagai contoh adalah game interaktif atau machinima, sebuah bentuk pembuatan film menggunakan virtual reality berbasis digital teknologi. Medium ini bersifat elektronis dan merupakan gabungan (hibrida) dari audiovisual, teks, dan sistem komputer. Kekuatan dari medium ini adalah adanya kemungkinan bagi penonton untuk berintaraksi dengan cerita yang dibangun (Hutcheon, 2006: 26). Ketika model medium-medium tersebut dikaitkan dalam sebuah relasi adaptasi, maka akan terbentuk pola:

- Telling $\longleftrightarrow$ Showing

Contoh: dari novel diadaptasi ke film/ drama pertunjukan (atau sebaliknya)

- Showing $\longleftrightarrow$ Showing

Contoh: dari film diadaptasi ke drama musikal (atau sebaliknya)

- Interacting $\longleftrightarrow$ Telling/ Showing

Contoh: dari game interatif diadaptasi ke film atau komik grafis (atau sebaliknya)

Pola yang terakhir merupakan adaptasi terbaru dalam rangka merespon kemunculan media baru berupa teknologi digital yang semakin canggih (Hutcheon, 2006: 3258).

\section{Adaptasi, Ekranisasi, dan Alih Wahana}

Pamusuk Eneste dalam bukunya yang berjudul Novel dan Film (1991), memperke- 
nalkan istilah ekranisasi untuk menyebut proses adaptasi dari karya sastra menjadi film. Istilah ini sendiri sebenarnya berasal dari bahasa Prancis, Ècran yang berarti layar. Eneste mengistilahkan bahwa ekranisasi adalah suatu proses pelayar-putihan atau pemindahan/pengangkatan sebuah novel ke dalam film (Eneste, 1991: 60). Ia juga menyebutkan bahwa pemindahan dari novel ke film mau tidak mau menimbulkan berbagai perubahan, antara lain perubahan dalam bentuk penambahan, pengurangan atau penciutan, dan perubahan berbagai variasi sebagai akibat dari pemadatan peristiwa dan durasi. Peralihan dari satu jenis kesenian menjadi bentuk kesenian yang lain ini senada dengan istilah alih wahana seperti yang dikemukakan oleh Sapardi Djoko Damono.

Damono menyebutkan alih wahana sebagai sebuah proses perubahan dari satu jenis kesenian ke dalam jenis kesenian lain (Damono, 2005: 96). Wahana berarti kendaraan, jadi alih wahana adalah proses pengalihan dari satu jenis 'kendaraan' ke jenis 'kendaraan' lain (Damono, 2012: 1). Lebih jauh Damono menjelaskan bahwa sebagai 'kendaraan', suatu karya seni merupakan alat yang bisa mengalihkan sesuatu dari satu tempat ke tempat yang lain. Wahana diartikan sebagai medium yang dipergunakan untuk mengungkapkan, mencapai, atau memamerkan gagasan atau perasaan. Jadi, inti dari alih wahana adalah pemindahan dan pengubahan.

Sesuatu yang dapat dialih dan dipindah-pindahkan ini dapat berupa karya seni apapun, baik berupa gagasan ataupun bentuknya. Sebagai contoh cerita fiksi diubah menjadi tari, drama, atau film. Alih wahana juga dapat dilakukan dari film ke novel, atau bahkan puisi yang lahir dari lukisan atau lagu dan sebaliknya. Lebih lanjut disebutkan bahwa di dalam alih wahana akan terjadi perubahan. Dengan kata lain, akan tampak perbedaan antara karya yang satu dan karya hasil alih wahana tersebut. Alih wahana novel ke film misalnya, tokoh, latar, alur, dialog, dan lain-lain harus diubah sedemikian rupa sehingga sesuai dengan keperluan jenis kesenian lain (Damono, 2005: 98).

\section{PENUTUP}

Dari beberapa model adaptasi yang dikemukakan oleh para pakar tersebut, menampakkan dua jenis hasil adaptasi yaitu: pertama, menitikberatkan pada kesetiaan (fidelity) pada sumber adaptasi; dan kedua, kontekstualitas-intertekstualitas sumber adaptasi yang menganggap sumber (asli) hanyalah sebagai titik tolak atau referensi untuk penciptaan produk (karya) baru. Adaptasi yang dikemukakan oleh Linda Hutcheon dan alih wahana dalam pandangan Sapardi Djoko Damono, tampaknya sama-sama tidak membatasi wilayah medium. Originalitas dalam karya adaptasi tidak hanya dinilai dari kesesuaian antara sumber dengan hasil karya yang baru, karena setelah proses adaptasi selesai, karya tersebut akan menjadi karya mandiri yang juga akan membangun kisahnya sendiri.

Adaptasi menunjukkan bahwa tidak ada satupun karya seni di dunia ini yang benar-benar baru dan berdiri sendiri, setiap karya seni tercipta dari karya-karya seni yang ada sebelumnya. Semua karya seni merupakan hasil dari proses adaptasi, sebuah pengulangan dengan variasi. Apa yang ada saat ini dalam bentuk film, tidak menutup kemungkinan besok akan menjadi karya pertunjukan panggung, dan lusa mungkin sudah dalam bentuk program televisi, atau menjadi game interaktif. Jaringan kreasi seperti itulah yang diharapkan tercipta dalam setiap proses adaptasi. Karya adaptasi akan diadaptasi ulang, begitu seterusnya sampai tak terbatas. 


\section{Daftar Pustaka}

Beja, Morris

1979 Film and Literature: an Introduction. New York: Longman.

Bluestone, George

1957 Novels into Film. Baltimore: Johns Hopkins Press.

Cartmell, Deborah \& Imelda Whelehan

1999 Adaptations: from Text to Screen, Screen to Text. London: Routledge.

Faubert, Patrick

2011 'Perfect Picture Material': Anthony Adverse and The Future of Adaptation Theory. Oxford Journals Adaptation (2011) 4 (2): 180-198. doi: 10.1093/ adaptation/apq018 First published online: November 22, 2010.

Hayward, Susan

2006 Cinema Studies: The Key Concepts, New York: Routledge.

Hutcheon, Linda

2006 The Theory of Adaptation. Roudledge, New York: Taylor \& Francis Group.

JB. Kristanto

2006 Katalog Film Indonesia 1926-2007. Bogor, Indonesia: PT Grafiasri Mukti.

Jenkins, Greg

1997 Stanley Kubrick and the Art of Adaptation: Three Novels, Three Films. North Carolina: Mc. Farland \& Co, Inc.
Klemm, Alexander J.

2009 From Text to Screen: Developing Early Film Language in D.W. Griffithûs Adaptation Enoch Arden. Thailand: Journal of University of the Thai Chamber of Commerce.

Pamusuk Eneste

1991 Novel dan Film. Jakarta: Nusa Indah.

Ray, Robert B.

2000 The Field of Literature and Film' Film Adaptation. Ed. James Naremore. NJ: Rutgers University Press.

Sanders, Julie

2006 Adaptation and Appropriation. New York: Routledge.

Sapardi Djoko Damono

2012 Alih Wahana. Jakarta: Editum.

2005 Pegangan Penelitian Sastra Bandingan. Jakarta: Pusat Bahasa.

Seger, Linda

1992 The Art of Adaptation: Turning Fact and Fiction into Film. New York: Holt Paperbacks.

Tibbetts, John C. \& James M. Welsh

2005 The Encyclopedia of Novels into Film, Facts on File. Ins, NY-USA.

Welsh, James M. \& Peter Lev (eds)

2007 The Literature/Film Reader: Issues of Adaptation. Scarecrow, Lanham (MD). 